\title{
Transient abnormal septal motion after non-surgical closure of the ductus arteriosus
}

\author{
SHINTARO BEPPU, YOSHIKAZU MASUDA, HIROSHI SAKAKIBARA, \\ SHIRO IZUMI, YUNG-DAE PARK, SEIKI NAGATA, KUNIO MIYATAKE, \\ YASUHARU NIMURA \\ From the National Cardiovascular Center, Research Institute and Hospital, Osaka, Japan
}

SUMMARY Abnormal septal motion on M mode echocardiography was seen in eight of 16 patients soon after non-surgical closure of the ductus arteriosus. Ten to twenty-nine months after the procedure the abnormal septal motion had disappeared spontaneously. The cross section of the left ventricular cavity was circular both when septal motion was abnormal and when it was normal. Cross sectional echocardiography showed that there was an exaggerated anterior swinging motion of the heart in systole in patients with abnormal septal motion on the $\mathrm{M}$ mode recordings. The left ventricular end diastolic diameter before closure was significantly larger, and its reduction after closure was more pronounced in those with abnormal septal motion than in those without. This suggested that the abnormal septal motion was associated with relief of long standing left ventricular volume overload. It is suggested that acute shrinkage of the heart caused temporary laxity of the pericardium, and consequently more movement of the heart within the thorax. The return of normal septal motion suggests that the pericardium gradually shrank to accommodate the smaller heart.

Abnormal motion of the interventricular septum is seen in $\mathbf{M}$ mode echocardiograms recorded in right ventricular volume overload, ${ }^{1-3}$ pericardial disease, ${ }^{4-8}$ intraventricular conduction disturbance, ${ }^{910}$ ischaemic heart disease, ${ }^{11-14}$ or after open chest cardiac surgery. ${ }^{15} 16$ We found transient abnormal septal motion in patients who had a ductus arteriosus closed by a catheter plugging method, ${ }^{17} 18$ which does not require thoracotomy.

\section{Patients and methods}

Sixteen patients (four men and 12 women; aged 1958 (mean 38)) had non-surgical closure of the ductus arteriosus with a plug guided by catheters. ${ }^{17} 18$ This method is not suitable for patients with severe pulmonary hypertension. No patient had an intraventricular conduction disturbance, either before or after the procedure.

Echocardiographic examinations were performed

Requests for reprints to Dr Shintaro Beppu, National Cardiovascular Center, Research Institute, 7-1 Fujishirodai, 5-chome, Suita, Osaka 565, Japan.

Accepted for publication 18 November 1987
1-51 days $(10(12))$ before and $1-13$ days $(7(3))$ after the ductus arteriosus had been plugged. Six patients were also examined 10-29 (16 (7)) months after closure.

We used a Toshiba SSH-11A or SSH-40A echocardiograph (both with a $2 \cdot 4 \mathrm{MHz}$ transducer). $M$ mode echocardiograms were recorded by a Toshiba LSR-20A strip chart recorder at a paper speed of $50 \mathrm{~mm} / \mathrm{s}$. Cross-sectional echocardiograms were recorded by a Victor BR-6400 video-tape recorder for subsequent frame analysis. The patients were examined in the left oblique decubitus position, at held expiration during normal breathing. The transducer was manipulated to obtain the short axis view of the left ventricle at the level of the tip of the papillary muscle. We took care to get a cross section that was perpendicular to the long axis of the left ventricle and on which the endocardial surface was clearly defined. After the real time images had been recorded on video tape, the ultrasound beam was directed to the centre of the left ventricle and the $M$ mode echocardiogram was recorded. We compared this technique with the standard technique for echocardiographic recording of interventricular septal motion. 


\section{MEASUREMENTS}

The systolic excursion of the interventricular septum was measured, with the leading edge of the left side of the ventricular septum as the reference point. The systolic phase was defined as the time from a peak of the $R$ wave of the electrocardiogram to the time when the left ventricular posterior wall was in its most anterior position. A negative or zero value for the systolic excursion was regarded as abnormal motion. The left ventricular diameter was measured at end diastole and end systole. The right ventricular diameter was measured as the distance from the right ventricular endocardial echoes to the right side of the ventricular septum on an end diastolic recording. The left atrial diameter was measured on the $M$ mode echocardiogram.

Cross sectional echocardiograms were reviewed frame by frame on a video digitiser connected to a Hewlett Packard model 9845 T desk top computer. It is known that the left ventricular cavity is deformed by right ventricular volume overload. ${ }^{19}$ To examine this deformation, the circumferential length and area of the left ventricle at end diastole and end systole were calculated by digitising the endocardial surface of the left ventricle.

$$
\text { Deformity index }=(\mathbf{A c}-\mathbf{A}) / \mathbf{A c} \times 100(\%)
$$

where $A$ is the cross sectional area of the left ventricular cavity and Ac the area of an assumed full circle of the same circumference as that for the actual area measured. The distance of the centre of gravity of the cross sectional area of the left ventricle from the

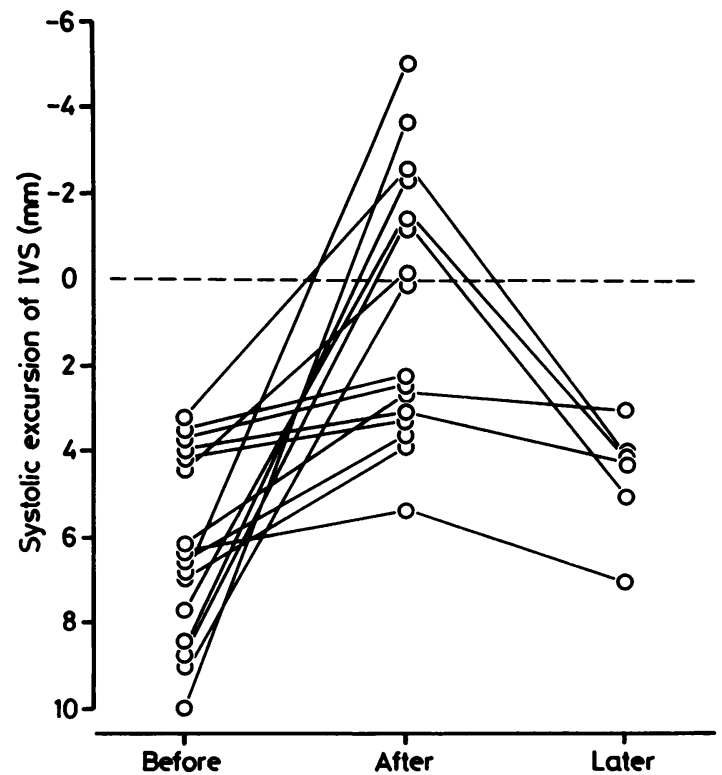

Fig 2 Systolic excursion of the interventricular septum (IVS) before closure, soon after closure, and later. Anterior excursion is shown as a negative value. Half the patients showed abnormal septal motion soon after closure but none of the six examined showed it later.

anterior chest wall was calculated automatically by the same digitising method. This is referred to as the centre of the heart. The systolic excursion of this centre was calculated from its end diastolic and end

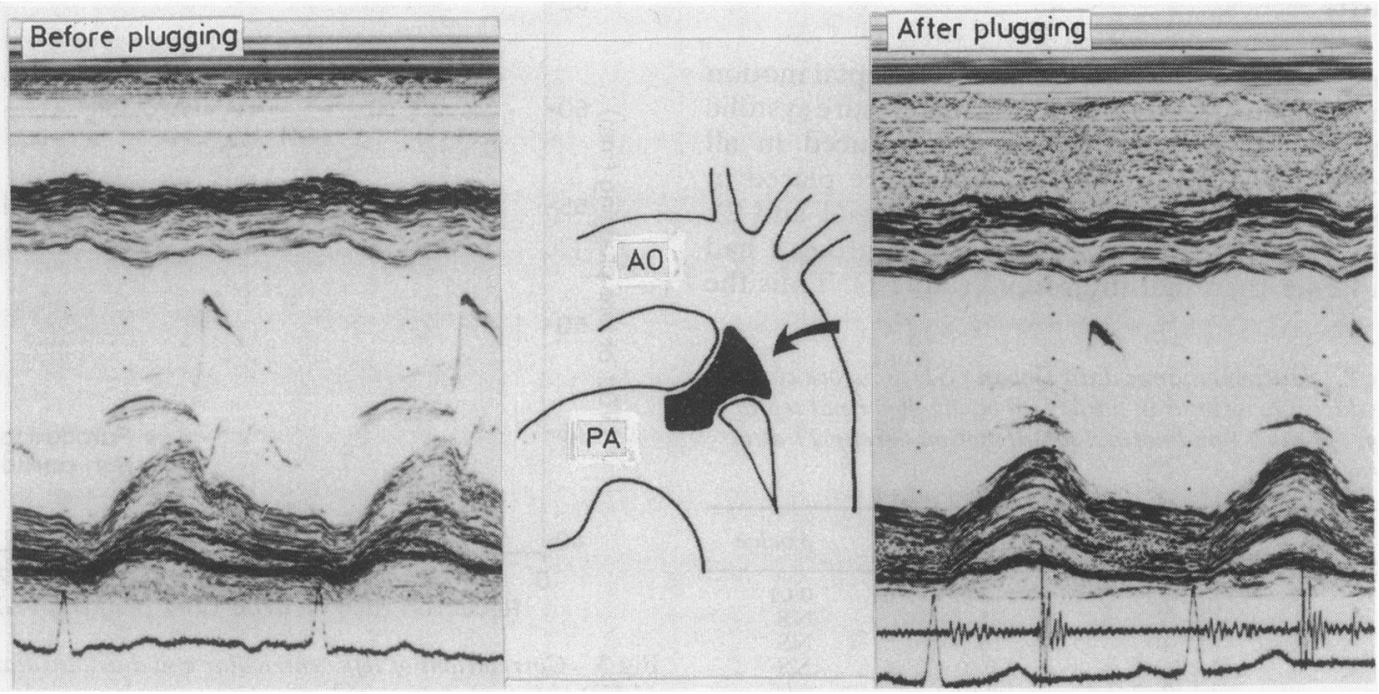

Fig 1 Representative $M$ mode echocardiograms before and soon after closure of the ductus arteriosus by the plugging method (shown schematically in the middle panel). There was abnormal septal motion after closure of the ductus but not before. AO, aorta; $P A$, pulmonary artery. 


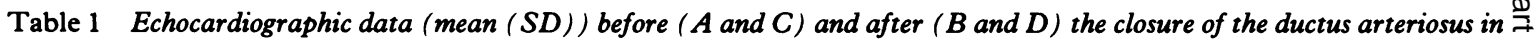
patients showing abnormal septal motion (group 1) and normal septal motion (group 2) soon after the procedure

\begin{tabular}{|c|c|c|c|c|c|c|c|c|}
\hline & \multicolumn{2}{|l|}{ Group 1} & \multicolumn{2}{|l|}{ Group 2} & \multicolumn{4}{|c|}{ p valve } \\
\hline & $\bar{A}$ & $B$ & $\bar{C}$ & $D$ & $\overline{A v / B}$ & $C v / D$ & $A v / C$ & $B v / D$ \\
\hline $\begin{array}{l}\text { IVSex (mm) } \\
\text { LVDd (mm) } \\
\text { LVDs (mm) } \\
\text { LAD (mm) } \\
\text { RVDd (mm) } \\
\text { Cex (mm) } \\
\text { DI }\end{array}$ & $\begin{array}{l}7 \cdot 2(2 \cdot 3) \\
60(3) \\
40(3) \\
41(6) \\
14(3) \\
0 \cdot 5(1 \cdot 4) \\
3 \cdot 8(0 \cdot 8)\end{array}$ & $\begin{array}{l}-2 \cdot 1(1 \cdot 7) \\
49(4) \\
39(4) \\
36(6) \\
18(5) \\
5 \cdot 3(2 \cdot 1) \\
3.9(0 \cdot 4)\end{array}$ & $\begin{array}{l}5.0(1 \cdot 3) \\
53(5) \\
33(3) \\
32(4) \\
16(5) \\
1.9(1 \cdot 2) \\
4.2(1 \cdot 2)\end{array}$ & $\begin{array}{l}3.3(0.9) \\
48(5) \\
33(4) \\
29(5) \\
19(5) \\
3.3(1.5) \\
4.5(1.0)\end{array}$ & $\begin{array}{l}0.005 \\
0.005 \\
\text { NS } \\
0.005 \\
0.025 \\
0.005 \\
\text { NS }\end{array}$ & $\begin{array}{l}0.005 \\
0.005 \\
\text { NS } \\
\text { NS } \\
0.025 \\
0.025 \\
\text { NS }\end{array}$ & $\begin{array}{l}0.05 \\
0.01 \\
0.01 \\
0.01 \\
\text { NS } \\
0.1 \\
\text { NS }\end{array}$ & $\begin{array}{l}0.001 \\
\text { NS } \\
0.02 \\
0.02 \\
\text { NS } \\
0.05 \\
\text { NS }\end{array}$ \\
\hline
\end{tabular}

IVSex, excursion of interventricular septum; LVDd, left ventricular end diastolic diameter; LVDs, left ventricular end diastolic diameter; LAD, left atrial diameter; RVDd, right ventricular end diastolic diameter; Cex, excursion of the "centre of gravity" of the cross section of the $\rightrightarrows$ left ventricle; DI, deformity index of the left ventricle.

systolic position, and this was used to express the entire motion of the heart.

Measurements from $M$ mode recordings and from the cross sectional recordings were performed independently by two examiners. The mean of 3-5 cardiac cycles was calculated for all measurements.

The patients were divided into two groups according to septal motion within two weeks of closure: group 1 had abnormal septal motion and group 2 did not.

The difference of the values obtained before and after closure in the same subjects was analysed by the paired $t$ test and the difference between the two groups was analysed by Student's $t$ test. Data were expressed as mean (SD), and a p value of $<0.05$ was regarded as statistically significant.

\section{Results}

Before closure of the ductus arteriosus septal motion was normal in all patients. Soon after closure systolic septal excursion was found to be reduced in all patients. As a result, eight patients were placed in group 1 and the other 8 in group 2 (figs 1 and 2). Before closure the systolic excursion in group 1 had been larger than that in group 2 (table 1 ). Thus the

Table 2 Haemodynamic data (mean (SD)) before closure of the ductus arteriosus in patients showing abnormal septal motion (group 1) and normal septal motion (group 2) after the procedure

\begin{tabular}{lccl}
\hline & Group 1 & Group 2 & p value \\
\hline LV & $142(11)$ & $113(17)$ & $0 \cdot 01$ \\
PA & $31(7)$ & $25(5)$ & NS \\
PAm & $21(8)$ & $16(4)$ & NS \\
CI & $4 \cdot 2(1.4)$ & $3.0(0.4)$ & NS \\
Qp/Qs & $2 \cdot 1(0.4)$ & $1.6(0.2)$ & 0.05
\end{tabular}

LV, left ventricular systolic pressure; PA, systolic pulmonary arterial pressure; PAm, mean pulmonary arterial pressure; $\mathrm{CI}$, cardiac index; $\mathrm{Qp} / \mathrm{Qs}$, pulmonary to systemic flow ratio. more exaggerated the posterior movement of the interventricular septum before closure, the more anteriorly the septum moved after closure (fig 2). Several months after closure, septal motion had 의 returned to normal in all patients.

Peak and mean pulmonary artery pressure before $\subseteq$ closure were almost normal, and there was no $\vec{D}$ difference between the groups 1 and 2 . The pulmon- $\vec{\theta}$ ary to systemic flow ratio was larger in group 1 than in group 2 (table 2). Because the flow ratio was 1.0 after closure, its change was larger in group 1 than in group 2. Cardiac output was similar in the two groups. The peak pressure of the left ventricle was higher in group 1 than in group 2.

Before closure the left ventricular end diastolic and end systolic diameters and left atrial diameter were

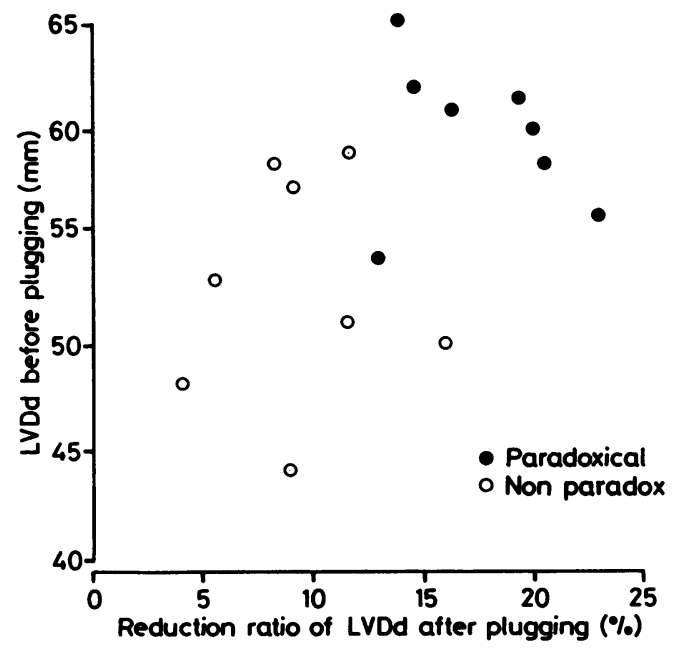

Fig 3 Correlations of left ventricular end diastolic diameter (LVDd) before closure and its reduction ratio soon after closure of the ductus. Patients with abnormal motion of the interventricular septum ( ) had different results from those without ( $O$ ). 




Fig 4 Short axis view of the left ventricle soon after closure of the ductus. This patient showed abnormal septal motion in $M$ mode echocardiograms. The left ventricular cavity was circular at both end diastole (ED) and end systole (ES). The left ventricle moves anteriorly in systole, as indicated by the overlapping images of the endocardial traces at end diastole (broken line) and end systole (solid line).

significantly larger in group 1 than in group $2(\mathrm{p}<$ 0.01 in each) (table 1). This difference was compatible with the difference in pulmonary to systemic flow ratio between the two groups. After closure, the left atrial diameter became significantly smaller in group $1(p<0.005)$ but was unchanged in group 2 . The left ventricular end diastolic diameter became significantly $(\mathrm{p}<0.005)$ smaller in both groups (by $18(3)^{\circ}{ }_{0}$ in group 1 and by $10(4) \%$ in group $2 ; \mathrm{p}<0.001)$.

We believe that septal motion became abnormal because the large left ventricular cavity that was present before closure was considerably reduced after closure of the ductus (fig 3).

The sizes of the right ventricular diameter before and after closure were similar in the two groups; and in both groups right ventricular diameter increased after closure ( $p<0.025$ ) (table 1$)$. The short axis cross sectional echocardiogram showed that the left ventricular cavity was almost circular throughout the cardiac cycle in all patients both before and after closure (fig 4). The deformity index of the left ventricle was similar before and after closure in groups 1 and 2 (table 1 ). These results indicate that deformation of the left ventricular cavity was not the cause of the abnormal septal motion.

The short axis view showed that the left ventricle moved anteriorly in systole in group 1 after closure (fig 4). The centre of the heart moved anteriorly in systole in both groups even before closure, though the magnitude of this movement was not significant. After closure of the ductus arteriosus the systolic anterior excursion increased significantly in both groups, but there was a larger increase in group 1 than in group 2 (table 1). This exaggerated anterior excursion did not persist; it was not seen 10-29 (mean 16(7)) months after closure. The systolic excursion of

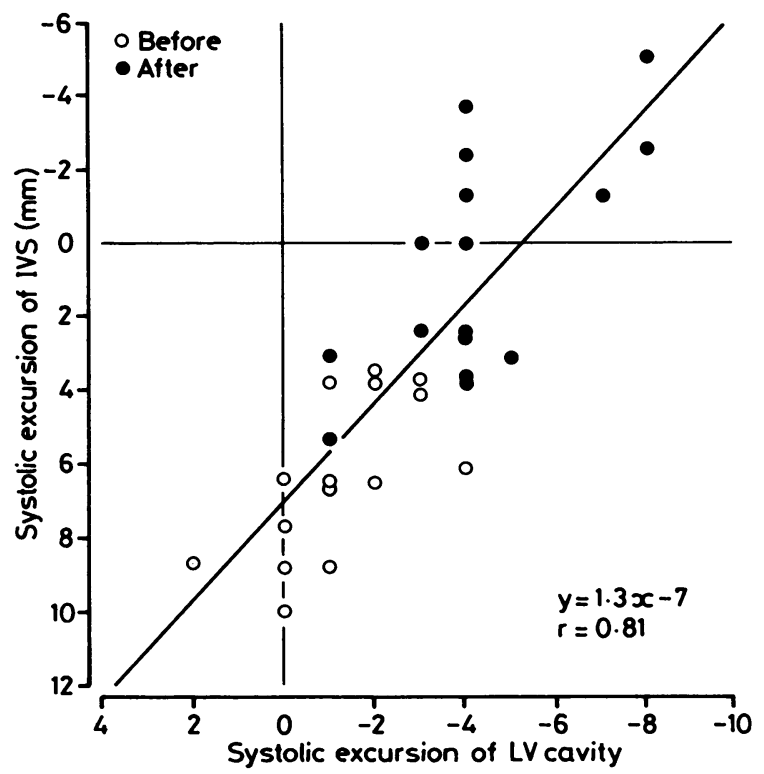

Fig 5 Relation between the systolic excursion of the ventricular septum (IVS) and that of the left ventricular cavity before (O) and soon after closure of the ductus (O) in all patients examined. The linear correlation $(r=0.81)$ was statistically significant $(p<0.01)$. 
the interventricular septum was closely correlated with that of the centre of the heart before and after closure ( $y=1.3 x-7, r=0.81$ ) (fig 5). Thus the abnormal septal motion was clearly caused by the exaggerated anterior motion of the heart.

\section{Discussion}

Septal motion can be abnormal in several conditions. It develops after therapeutic closure of the ductus ${ }^{20}$ but the mechanism for this phenomenon is not clear. Catheter plugging is a non-surgical method of closing the ductus arteriosus. ${ }^{17} 18$ The procedure does not cause intraventricular conduction disturbances, pericardial adhesion, or myocardial ischaemia, which may all cause abnormal septal motion. After closure of the patent ductus abnormal septal motion develops despite relief of abnormal hemodynamic function and disappears spontaneously some time later. We found that the abnormal septal motion in the present cases was a consequence of an anterior swinging motion of the heart and we have sought an explanation for this.

The severity of left ventricular volume overload before closure of the ductus is one possible explanation. The larger the left ventricular cavity before closure, the greater was the extent of abnormal motion after closure. Enlargement of the left ventricular and left atrial cavities owing to the ductus was significantly and rapidly reduced to normal by closure of the ductus. This acute change was associated with the development of abnormal septal motion.

Perhaps the reduction in size of the left heart induces relative right ventricular volume overload, which can cause abnormal septal motion. This is unlikely, however, because in our cases the right ventricular diameter was similar in the two study groups and the left ventricular cavity was almost circular in every patient. Deformation of the left ventricular cavity causes abnormal septal motion in patients with right ventricular volume overload. ${ }^{19}$

Shrinking of the heart caused by an acute reduction of long-standing left ventricular volume overload may cause the anterior motion of the heart. This feature resembles the abnormal septal motion seen in congenital absence of the pericardium. ${ }^{4}$ Cross sectional echocardiograms showed that this results from the exaggerated systolic anterior motion of the heart, ${ }^{21} 22$ possibly attributable to excessive posterior movement of the heart during diastole in the absence of pericardial support. In addition, the short axis cross section of the left ventricle was circular in all phases of the cardiac cycle in congenital absence of the pericardium..$^{22}$ This was also characteristic of our patients with abnormal septal motion. The pericarSakakibara, Izumi, Park, Nagata, Miyatake, Nimura
dium in a patient with ductus arteriosus may be stretched by the long-standing volume overload of the left ventricle. Closure of the ductus relieves the left ventricular volume overload and the heart $\frac{\text { of }}{9}$ rapidly becomes smaller. The pericardium, however, $\bar{c}$ does not shrink as rapidly, ${ }^{23}$ and it becomes lax. Movement of the heart without pericardial restraint $\frac{\bar{c}}{\frac{1}{a}}$ results in a swinging motion of the heart, as it does $\mathbb{Q}$ when there is no pericardium. Because we saw abnormal septal motion for only a short period after $\vec{A}$ closure of the ductus we think that gradual shrinkage $?$ of the pericardium to the size of the heart leads to the $\vec{\omega}$ disappearance of the abnormal swinging motion that $\stackrel{\circ}{\circ}$ is manifested by the abnormal septal motion on the echocardiogram.

We thank Dr Makoto Takamiya and Dr Mitsushige Ohta, the radiologists who performed the presento ductus closures by the catheter method.

This work was partly supported by a ResearchGrant for Cardiovascular Disease from the Ministry of Health and Welfare.

\section{References}

1 Diamond MA, Dillon JC, Haine CL, Chang S, Feigenbaum $H$. Echocardiographic features of atrial septa defect. Circulation 1971;43:129-35.

2 Meyer RA, Schwartz DC, Benzing G III, Kaplan S@ Ventricular septum in right ventricular volume overload. An echocardiographic study. Am J Cardiog 1972;30:349-53.

3 Tajik AJ, Gau GT, Ritter DG, Schattenberg TT Echocardiographic pattern of right ventricular dias tolic volume overload in children. Circulation 1972? 46:36-43.

4 Payvandi MN, Kerber RE. Echocardiography in con $\frac{\overrightarrow{0}}{6}$ genital and acquired absence of the pericardium 3 . Circulation 1976;53:86-92.

5 Voelkel AG, Pietro DA, Folland ED, Fisher ML, Paris AF. Echocardiographic features of constrictive pericarditis. Circulation 1978;58:871-5.

6 Candell-Riera J, Garcia del Castillo H, Permanyer 7 Miralda G, Soler-Soler J. Echocardiographic features. of the interventricular septum in chronic constrictivo pericarditis. Circulation 1978;57:1154-8.

7 Schnittger I, Bowden RE, Abrams J, Popp RL N Echocardiography: pericardial thickening and con $\frac{N}{\mathrm{E}}$ strictive pericarditis. Am J Cardiol 1978;42:388-95. O-

8 Horowitz MS, Rossen R, Harrison DC. Echocardiographic diagnosis of pericardial disease. Am Heart 1979;97:420-7.

9 Abbasi AS, Eber LM, MacAlpin RN, Kattus AA:? Paradoxical motion of interventricular septum in lef. bundle branch block. Circulation 1974;49:423-7.

10 Zoneraich S, Zoneraich O, Rhee JJ. Echocardiographi@

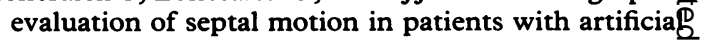
pace-makers: vectorcardiographic correlations. $A$ me Heart J 1977;93:596-602. 
11 Corya BC, Rasmussen S, Knoebel SB, Feigenbaum H, Black MJ. Echocardiography in acute myocardial infarction. Am J Cardiol 1975;36:1-10.

12 Kerber RE, Marcus ML, Wilson R, Ehrhardt J, Abboud FM. Effects of acute coronary occlusion on the motion and perfusion of the normal and ischemic interventricular septum. A experimental echocardiographic study. Circulation 1976;54:928-35.

13 Joffe CD, Brik H, Teichholz LE, Herman MV, Gorlin R. Echocardiographic diagnosis of left anterior descending coronary artery disease. Am J Cardiol 1977;40:11-6.

14 Kolibash AJ, Beaver BM, Fulkerson P, Khullar S, Leighton RF. The relationship between abnormal echocardiographic septal motion and myocardial perfusion in patients with significant obstruction of the left anterior descending artery. Circulation 1977;56:780-5.

15 Waggoner AD, Shah AA, Schuessler JS, et al. Effect of cardiac surgery on ventricular septal motion: assessment by intraoperative echocardiography and crosssectional two-dimensional echocardiography. Am Heart $J$ 1982;104:1271-8.

16 Kerber RE, Litchfield R. Postoperative abnormalities of interventricular septal motion: two-dimensional and M-mode echocardiographic correlations. $\mathrm{Am}$ Heart $J$ 1982;104:263-8.
17 Porstmann W, Wierny L, Warnke H, Gerstberger G, Romaniuk PA. Catheter closure of patent ductus arteriosus. 62 cases treated without thoracotomy. Radiol Clin North Am 1971;9:203-18.

18 Sato K, Fujino M, Kozuka T, et al. Transfemoral plug closure of patent ductus arteriosus. Experiences in 61 consecutive cases treated without thoracotomy. Circulation 1975;51:337-41.

19 Weyman AE, Wann S, Feigenbaum H, Dillon JC. Mechanism of abnormal septal motion in patients with right ventricular volume overload. A crosssectional echocardiographic study. Circulation 1976;54:179-86.

20 Itaya $M$, Ifuku $M$, Toshima $H$, Takahashi $H$, Koga $Y$, Ohishi K. Abnormal septal motion following nonsurgical closure of the patent ductus arteriosus. $J$ Cardiogr 1984;14(suppl 4):75-83.

21 Nicolosi GL, Borgioni L, Alberti E, et al. M-mode and two-dimensional echocardiography in congenital absence of the pericardium. Chest 1982;81:610-3.

22 Beppu S, Matsuhisa M, Izumi S, et al. Pericardial defect. Roles of the pericardium on kinetoanatomic changes of the heart influenced by patients' postures. J Cardiogr 1986;16:193-205.

23 Shabetai R, Mangiardi L, Bhargava V, Ross J Jr, Higgins CB. The pericardium and cardiac function. Prog Cardiovasc Dis 1979;22:107-34. 